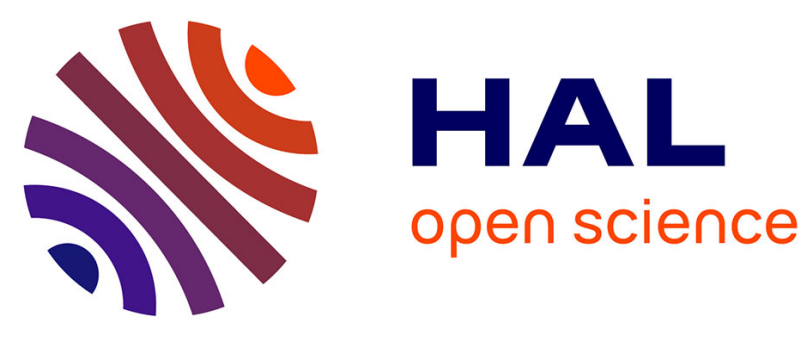

\title{
Salivary flow decreases in healthy elderly people independently of dental status and drug intake
}

Mathilde Vandenberghe-Descamps, Hélène Labouré, Aurélie Prot, Chantal Septier, Carole Tournier, Gilles Feron, Claire Sulmont-Rossé

\section{To cite this version:}

Mathilde Vandenberghe-Descamps, Hélène Labouré, Aurélie Prot, Chantal Septier, Carole Tournier, et al.. Salivary flow decreases in healthy elderly people independently of dental status and drug intake. Journal of Texture Studies, 2016, 47 (4), pp.353-360. 10.1111/jtxs.12191 hal-02637663

\section{HAL Id: hal-02637663 https://hal.inrae.fr/hal-02637663}

Submitted on 3 Mar 2021

HAL is a multi-disciplinary open access archive for the deposit and dissemination of scientific research documents, whether they are published or not. The documents may come from teaching and research institutions in France or abroad, or from public or private research centers.
L'archive ouverte pluridisciplinaire HAL, est destinée au dépôt et à la diffusion de documents scientifiques de niveau recherche, publiés ou non, émanant des établissements d'enseignement et de recherche français ou étrangers, des laboratoires publics ou privés. 


\section{Titre: Salivary flow decreases in healthy elderly people independently of dental status and drug intake}

Sous-titre: Salivary flow decreases in healthy elderly people

Auteurs: Mathilde Vandenberghe-Descamps, Hélène Labouré, Aurélie Prot, Chantal Septier, Carole Tournier, Gilles Feron, Claire Sulmont-Rossé

Rattachement institutionnel: Centre des Sciences du Goût et de l'Alimentation, AgroSup Dijon, CNRS, INRAE, Université Bourgogne Franche-Comté, F-21000 Dijon, France.

Mots-clefs: healthy ageing, older adults, young adults, saliva, hyposalivation, oral health

DOI: $\underline{10.1111 / j \text { txs.12191 }}$

\section{Résumé:}

In humans, oral food consumption is by far the most important point where food's organoleptic properties can be perceived and can elicit sensory pleasure. It is also the ultimate stage of the food supply chain and the beginning of the food disintegration and digestion process. However, in regard to the influence of ageing on food oral processing, this topic has been mainly investigating through mastication, whereas salivation remains largely unexplored. The present experiment aimed at studying the impact of normal ageing on salivary flow taking into account the dental status and the number of drugs taken by the elderly people. This was achieved by comparing resting and stimulated salivary flows of young versus healthy elderly adults (i.e., autonomous elderly people without acute pathology). Ninety-three young adults (22-55 years old) and 84 elderly people (70-92 years old) underwent a measurement of resting and stimulated salivary flows and an oral examination (teeth counting; functional unit counting i.e., counting occluding tooth pairs). The present study showed an average $38.5 \%$ reduction of resting salivary flow and $38.0 \%$ reduction of stimulated salivary flow in healthy elderly people compared to young adults. This reduction was observed independently of the dental status and drug intake: elderly people presented reduced salivary flow even if they did not take any drugs or if their dental status was similar to the one of the young adults. The results also highlight a large inter-individual variability both in young and elderly adults.

\section{Practical applications}

During oral food consumption, saliva plays a key role in the acceptance of food and beverage by modulating the perception of texture, taste and aroma, as well as providing eating comfort by assisting the food breakdown process into a bolus that can be safely swallowed. However, in regard to the influence of ageing on food oral processing, the present results demonstrate a reduced salivary flow in healthy elderly people. Consequently, there is a need for developing foods tailored to the salivary capacities of elderly people aside from the efforts put into the development of foods tailored to the mastication and swallowing abilities of this population. In fact, in the context of an ageing population, the development of products meeting an elderly person's functional capacities becomes a major challenge for the food industry as well as for society. 


\section{INTRODUCTION}

In humans, oral food consumption is by far the most important point where food's organoleptic properties (texture, taste, and aroma) can be perceived and elicit sensory pleasure. It is also the ultimate stage of the food supply chain and the beginning of the food disintegration and digestion process (Chen, 2009). The different mechanisms involved in oral food consumption, which is referred to as "food oral processing", depend both on the food's structure and the individual's oral physiology (Salles et al., 2011). However, in regard to the influence of ageing on food oral processing, this topic has been mainly investigating through mastication whereas salivation remains largely unexplored.

Saliva is a physiological fluid that plays a crucial role in preserving and maintaining oral health and eating comfort (Carpenter, 2012). Saliva is secreted by three major salivary glands (submandibular, sublingual and parotid glands) and several minor salivary glands located all over the oral cavity (Christensen, 1986). During oral food consumption, saliva has three major functions. First, saliva plays a key role in the acceptance of food and beverage by modulating the perception of oral sensations (taste, viscosity, smoothness, juiciness, astringency, etc.) and aroma release. In fact, taste compounds should be in an aqueous solution to reach and activate taste buds (Fischer et al., 1994), and it has been demonstrated that taste sensitivity is related to saliva composition (Dsamou et al., 2012). Furthermore, texture perception is influenced by saliva composition. Engelen et al. (2007) have demonstrated that subjects with a high $\alpha$ amylase activity had a decreased thickness perception of a starch-based custard. Finally, saliva can impact aroma release by assisting in the food breakdown process, by retaining or releasing aroma compounds depending on their affinity with saliva, and by inducing chemical reactions likely to produce new volatile compounds (Gierczynski et al., 2011). Second, saliva, as well as mastication, transforms a food sample into a bolus that can be safely swallowed (Prinz and Lucas, 1997). The water in saliva moistens the food particles, whereas the salivary mucins bind masticated food into a coherent and slippery bolus that can easily slide through the oesophagus without damaging the mucosa. Saliva enzymes also initiate the digestion of carbohydrates and triglycerides in the food bolus (Salt and Schenker, 1976; Hamosh and Burns, 1977). Third, saliva dilutes and removes substances from the oral cavity after swallowing ("oral clearance"; Lagerlof and Oliveby, 1994; Lenander-Lumikari and Loimaranta, 2000). In fact, salivation and swallowing are acknowledged to be important processes for eliminating injurious and noxious agents and bacteria from the oral cavity (Pedersen et al., 2002). Saliva clears sugar and acids from the oral cavity and thereby protects teeth from erosion. Finally, teeth and mucous membranes are covered by a protective film of saliva, which prevents the occurrence of caries (Ericsson, 1953).

In elderly people, it has been demonstrated that the cumulative effect of ageing and associated changes, such as tooth loss (Dormenval et al., 1998; Srinivasulu et al., 2014), drug intake (Handelman et al., 1989; Bardow et al., 2001; Johanson et al., 2015; Thomson, 2015) and disease (Ship et al., 1990; Ship, 1992; Ship and Puckett, 1994; Chu et al., 2015), may affect salivary flow. However, to the best of our knowledge, very few studies (if not)have investigated the impact of normal ageing on salivary flow taking into account the dental status and the number of drugs taken by the elderly people. In these studies, many methods were used to measure the salivary flow. Therefore, a comparison of the results is difficult to make. Moreover, none of the studies have explored the relationship between dental status and salivary flow in elderly people.

Consequently, the present experiment aimed at studying the impact of normal ageing on salivary flow taking into account dental status and the number of drugs taken by the elderly 
people. This was achieved by comparing resting and stimulated salivary flows of young versus healthy elderly adults (i.e., autonomous elderly people without acute pathology).

\section{MATERIALS AND METHODS}

\section{Participants}

Young adult panel. A panel of young adult volunteers $(n=93)$ was recruited in Dijon during a period of two months. The recruitment criteria were the following: aged between 20 and 55 years and good dental status (no missing teeth except the third molar, no occlusion disorders, and no daily drug intake). An interview was carried out with each volunteer to ensure that they met the inclusion criteria.

Elderly adult panel. The data were collected as part of a programme aimed at studying the relationship between oral health and eating behaviour (AlimaSSenS project: towards an adapted and healthy food supply for elderly people). A panel of elderly volunteers $(n=84)$ was recruited from a population of elderly people living at home in Dijon during a period of six months. The recruitment criteria were the following: older than 70 years old, no acute pathological episodes at the time of the experiment, and scoring at least 24 on the Mini Mental State Evaluation (MMSE) (Folstein et al. 1975). An interview was carried out with each volunteer to ensure that they met the inclusion criteria.

\section{Procedure}

Young adult volunteers underwent a salivary flow test (resting and stimulated). The session was organized as a face-to-face interview that was conducted by 3 experimenters who had previously participated in a 1-day training session.

Elderly adult volunteers took part in one session with a duration of approximately one hour and thirty minutes. During this session, participants completed the Geriatric Oral Health Assessment Index (GOHAI), which is a questionnaire that evaluates self-perception of oral health (Slade and Spencer, 1994; Tubert-Jeannin et al., 2003). The participants were also interviewed on their food habits and drug intake. Then, the participants sat in an articulated resting chair, and a trained experimenter carried out the oral examination (teeth counting and functional unit counting). Finally, the participants completed the xerostomia questionnaire (Thomson et al., 1999) and performed a measure of salivary flow (resting and stimulated). The sessions were organized as face-to-face interviews that were conducted by 3 experimenters (all women) who had previously participated in a 4-hour long training session.

\section{Measurements}

Salivary flow. Resting and stimulated salivary flows were measured as previously described (Feron et al., 2014; Neyraud et al., 2012). The participants were asked not to smoke, eat or drink at least one hour before collecting the saliva. Resting salivary flow was measured by instructing the participant to spit out the saliva into a pre-weighed screw-cap cup every time they felt like swallowing over a period of 5 minutes for the young adults and 10 minutes for the elderly participants. Stimulated salivary flow was measured by instructing the participants to masticate a piece of pre-weighed parafilm while spitting out the saliva into a pre-weighed screw-cap cup every time they felt like swallowing over a period of 5 minutes. Cups were weighed, and salivary flow rates were expressed in $\mathrm{ml} / \mathrm{min}$ assuming that one $\mathrm{g}$ of saliva corresponds to one $\mathrm{ml}$. 
Teeth counting. A trained experimenter counted the number of natural, restored and fixed prosthetic teeth (participants who wore dentures were asked to remove them for this measure).

Functional unit counting. A functional unit was defined as a pair of posterior antagonist teeth that had at least one contact area during chewing. The number of functional units was evaluated by asking the participants to chew 1-2 cycles on $200-\mu \mathrm{m}$ thick articulating paper; the number of teeth on the mandibular arch that had at least one colour mark provided the number of functional units. The participants with dentures were asked if they had used their dentures while eating during their three last meals. Those who had not done so were asked to remove their dentures before completing this measure.

\section{Data analysis}

Student's $t$-tests were performed using the TTEST procedure provided in the SAS software (SAS Institute INC., Cary, NC, USA). Equality of variance was first assessed by using a folded form of the F statistic (Steel and Robert, 1980). Depending on the results, groups were compared using the $t$ statistic when the variances were equal or the Cochran and Cox (1950) approximation when the variances were unequal. Analyses of variance (ANOVA) were done using the GLM procedure provided in the SAS software (ss3 option). Post-hoc analyses were performed using the Student Newman Keuls test. Means (M) are associated with the standard error of the mean (SEM). The threshold for significance was set to 5\%.

\section{RESULTS}

Ninety-three young adults (48 women and 45 men) and 84 elderly participants were included (47 men and 37 women). No significant differences were observed regarding sex distribution $\left(\chi^{2}=1.01 ; \mathrm{ns}\right)$. Characteristics of the participants are summarized in the Table 1. As expected, the dental status of the young participants was better than that of the elderly participants (number of missing teeth for young adults: 0 ).

\section{Table 1 about here}

\section{Impact of ageing on salivary flow}

Figure 1 presents the box-plot distributions of the resting and stimulated salivary flow for the young and elderly panels. The box-plot distributions reveal a median difference but also a larger variability for the young adult participants for both the resting and stimulated salivary flow. Actually, variances in age groups were significantly unequal for the stimulated flow $[F(92,83)=2.11 ; p<0.001]$ but not for the resting flow $[F(92,83)=1.35 ; p=0.17]$. Both the resting and stimulated salivary flow were lower in the elderly participants than in the young participants [resting: $t(175)=6.00 ; p<0.001$; stimulated: $t(164)=6.91 ; p<0.001$ ]

With regard to resting salivary flow, no impact of sex was observed for the elderly participants $[t(78)=-0.30 ; p=0.76 ; \mathrm{M}=0.30 \mathrm{ml} / \mathrm{min} \pm 0.03 ; \mathrm{M}=0.31 \mathrm{ml} / \mathrm{min} \pm 0.03$, for elderly women and elderly men, respectively], while a tendency was observed for the young participants $[t(90)=-1.76 ; p=0.08]$, with young women tending to have a lower resting flow $[\mathrm{M}=0.46 \mathrm{ml} / \mathrm{min} \pm 0.03]$ than young $\mathrm{men}[\mathrm{M}=0.54 \mathrm{ml} / \mathrm{min} \pm 0.03]$. With regard to stimulated salivary flow, a significant impact of sex was observed for both the young $[t(86)=-2.15$; $p<0.05]$ and elderly participants [ $t(82)=-2.20 ; p<0.05]$, with women having a reduced stimulated flow [young: $\mathrm{M}=2.24 \mathrm{ml} / \mathrm{min} \pm 0.14$; elderly: $\mathrm{M}=1.34 \mathrm{ml} / \mathrm{min} \pm 0.10$ ] compared with men [young: $\mathrm{M}=2.70 \mathrm{ml} / \mathrm{min} \pm 0.17$; elderly: $\mathrm{M}=1.67 \mathrm{ml} / \mathrm{min} \pm 0.12$ ] 


\section{Figure 1 about here}

\section{Impact of ageing versus dental status and drug intake on salivary flow}

To further study the impact of dental status, two sub-groups were considered among the elderly participants: elderly participants with a good dental status, which had 7 or more posterior functional units and no dentures $(n=27)$, and elderly participants with a poor dental status, which had 4 or fewer posterior functional units $(n=19)$. The thresholds of 7 and 4 functional units to define good and bad dental status, respectively, were defined according to Leake et al. (1994). It should be noted that all 93 young adults presented 7 or more posterior functional units. Figure 2 presents the resting and stimulated salivary flow for the young adults and each elderly dental group. The ANOVA revealed a significant group effect (resting: $F(2,136)=16.40 ; p<0.001$; stimulated: $F(2,136)=16.11 ; p<0.001)$. According to the post-hoc analyses, the salivary flows of young adults were significantly greater than the salivary flows of elderly people regardless of their dental status. No significant effect of dental status was observed in the elderly participants.

\section{Figure 2}

To investigate the impact of drug intake, two subgroups were considered among the elderly participants: elderly participants not taking any drugs $(n=19)$ and elderly participants taking at least 4 or more drugs per day $(n=28)$. The thresholds of intake of 4 or more drugs per day was defined according to Handelman et al. (1989) who showed a significant decrease in stimulated salivary in elderly people taking four drugs per day. It should be noted that none of the 93 young adults took drugs during the time of the experiment. Figure 3 presents resting and stimulated salivary flow for young adults and each elderly drug intake group. The ANOVA revealed a significant group effect (resting: $F(2,137)=13.02 ; p<0.001$; stimulated: $F(2,137)=16.07 ; p<0.001)$. According to the post-hoc analyses, the salivary flows of young adults were significantly greater than salivary flows of elderly people whether they took drugs or not. No significant effect of drug intake was observed within the elderly population recruited for this study.

\section{Figure 3}

\section{DISCUSSION}

The present study showed, on average, a 38.5\% reduction in the resting salivary flow and $38.0 \%$ for the stimulated salivary flow in healthy elderly people compared with young adults. This reduction was observed independently of drug intake and the dental status: elderly people presented a reduced salivary flow even if they did not take any drugs or if their dental status was similar to the one of the young adults. These results support the results of Affoo et al. (2015) who recently conducted a meta-analysis on the impact of ageing on salivary flow. According to Affoo et al., ageing is associated with reduced salivary flow that cannot be fully explained by drug intake or disease (dental status was not explored). In fact, from a biological standpoint, ageing is accompanied by structural changes in the salivary glands, such as a reduction in acinar volume, a loss of secretory tissue and an increase of adiposity (Scott, 1986; Scott et al., 1987). Furthermore, it has been suggested that age-related neurophysiological changes may account for the changes in salivary secretion (Baum, 1987). However, further studies are needed to clarify the link between these changes and saliva secretion in elderly people and to uncover the mechanisms beyond the impact of ageing per se on salivary flow. 
Beyond these age-related processes, it has been demonstrated that drug intake may have a strong impact on saliva flow (Handelman et al., 1989; Bardow et al., 2001; Johanson et al., 2015; Thomson, 2015). According to Sreebny and Schwartz (1997), 42 drug categories and 56 subcategories are known to be xerogenic, i.e., inhibit saliva secretion through various pathways. In fact, Handelman et al. (1989) observed that participants who took more than three drugs per day had a stimulated salivary flow significantly less than participants who did not take any drugs. However, in the present experiment, no difference was observed between elderly people who did not take any drugs and elderly people who took more than three drugs per day. A similar result was previously observed by Nagler and Hershkovich (2005) who observed no significant difference in the resting salivary flow between drug-free elderly participants and elderly people who were taking drugs. This study included 28 subjects aged between 60 and 90 years old with an average age of 75.8 years with 14 participants that were drug free and 14 participants that consumed drugs (patients treated routinely).

In the same way, previous studies have demonstrated a correlation between the number of remaining teeth and a reduction in the salivary flow in an elderly population (Ikebe et al., 2011; Samnieng et al., 2012). Interestingly, whereas some authors have hypothesized that the age-related decline in bite strength may result in less stimulation of salivary glands and, thus, in a reduced salivary flow (Affoo et al., 2015). Other authors have demonstrated that elderly people with a low salivary flow rate were more likely to lose teeth (Caplan and Hunt, 1996). However, in the present experiment, no correlation was observed between the dental status and the saliva flow. Furthermore, Flink et al. (2008) showed a relation only in the case of severely reduced salivary flow among women over 50 years old. The author proposed that this link was mainly explained by the development of caries due to a lack of saliva secretion and, thus, protection.

The present study included "healthy" elderly people: older adults who lived independently at home, who did not suffer from an acute pathology (e.g., no cancer) or dementia (e.g., Alzheimer' disease) and who had a good nutritional status. Indeed, the mean MMSE score for the present sample was 28.7 out of 30; no participant scored below 25 (the MMSE screens for cognitive impairment; scores that are greater than or equal to 25 points indicate normal cognition). The mean MNA score of the present sample was 27.3 out of 30 ; only two participants were at risk for malnutrition (the MNA screens for malnutrition; scores that are greater than or equal to 24 points indicate normal nutritional status; scores that range from 17 to 23.5 indicate a risk of malnutrition, and scores below 17 points indicate malnutrition). This means that these participants were free from any pathology. In fact, 65 of the participants took an average of 3.6 drugs per day mainly for chronic diseases, such as hypertension. However, the present sample may be quite free of confounding factors that are often associated with drug intake and/or poor dental status, such as poor nutritional status, decline in general health, onset of neurological disorders. This question of confounding factors was evidenced in the study conducted by Flink et al. (2008) on 1247 volunteers and considered similar variables as the ones in the present study. The authors showed that, for instance, in young adults (less than 50 years old) drug intake did not explain the decrease in salivary flow. The authors suggest the involvement of other variables, such as body mass index greater than $25 \mathrm{~kg} / \mathrm{m}^{2}$, malnutrition and disease. For instance, the authors showed that the only variable that explained a very low stimulated salivary flow in a subset of this population was a diagnosed disease. Conversely, in the same study, the effect of drugs on salivary flow was demonstrated in the older population (65 to 69 years old), but in this population, an average of $52 \%$ of women and $58 \%$ of men with a disease had poor general health. 
Finally, the present experiment highlighted the large inter-individual variability both in the young and elderly panel. Among the elderly panel, 13\% of the participants were suffering from hyposalivation (resting salivary flow less than $0.1 \mathrm{ml} / \mathrm{min}$ ), whereas $18 \%$ of the participants had a salivary flow greater than the mean salivary flow of the young panel. A similar conclusion was performed by Flink et al. (2008). In their best model predicting a very low unstimulated salivary flow rate, the independent variables explained only $10 \%$ of the difference between individuals. Two types of factors can be proposed to account for the variability observed in the elderly panel for the salivary flow (Figure 4):

- Life-style factors, such as diet or smoking habits. In fact, Ernest (1993) showed a positive relationship between flow rate and the intake of 18 out of 22 nutrients, with a highly significant correlation for calories, protein, carbohydrates and vitamin C and B6 , amongst others. Moreover, it has been demonstrated that a modification in diet (liquid, less acidogenic or firmer texture) can either increase or decrease the salivary flow (Dodds et al., 2005). Regarding smoking habits, the salivary flow rate was significantly reduced in long-term smokers (mean salivary flow: $0.38 \mathrm{ml} / \mathrm{min}$ ) compared to non-smokers $(0.56 \mathrm{ml} / \mathrm{min})$ ( $\operatorname{Rad}$ et al., 2010).

- Ageing factors including ageing-related processes, such as the hydration status (Buffa et al., 2011), structural changes in the salivary glands, neurophysiological changes or ageing-related events, such as the onset of a pathology or dementia, may impact the salivary flow directly or indirectly through drug intake.

However, longitudinal studies are expected to decipher the correlation between the salivary flow of young and older adults, and, namely, whether individuals who have the greatest salivary flows when they are young will have reduced but still the greatest salivary flows when older compared with their age group. Furthermore, studies are expected to disentangle the relative impact of each factor on the reduction of the salivary flow in an elderly population.

\section{Ethical Statements}

The authors declare that they do not have any conflicts of interest. For the young panel, the experimental protocol was approved by the French Ethics Committee for Research (Comité de Protection des Personnes Est-1 $\left.\mathrm{N}^{\circ} 2008 / 15\right)$ and by the Direction Générale de la Santé, France ( ${ }^{\circ}$ DGS2008-0196). For the elderly panel, the experimental protocol was approved by the French Ethics Committee for Research (CPP Est III, Nancy, \#15.04.04, ANSM \#2015A00279-40). In accordance with ethical standards, all participants received written and oral information on the study before signing a consent form.

\section{Acknowledgements}

This study is part of SensInMouth [ANR-07-PNRA-014] and AlimaSSenS [ANR-14-CE20-0003-01] funded by the French National Research Agency. This work was also supported by the Regional Council of Burgundy and the European Funding for Regional Economical Development. 


\section{References}

AFFOO, R.H., FOLEY, N., GARRICK, R., SIQUEIRA, W.L. and MARTIN, R.E. 2015. Meta-Analysis of Salivary Flow Rates in Young and Older Adults. J Am Geriatr Soc. 63, 2142-51.

BARDOW, A., NYVAD, B. and NAUNTOFTE, B. 2001. Relationships between medication intake, complaints of dry mouth, salivary flow rate and composition, and the rate of tooth demineralization in situ. Archives of Oral Biology. 46, 413-423.

BAUM, B.J. 1987. Neurotransmitter control of secretion. J Dent Res. 66, 628-32.

BUFFA, R., FLORIS, G.U., PUTZU, P.F. and MARINI, E. 2011. Body composition variations in ageing. Coll antropol 35(1), 259-65.

CAPLAN, D.J. and HUNT, R.J. 1996. Salivary flow and risk of tooth loss in an elderly population. Community Dent Oral Epidemiol. 24, 68-71.

CARPENTER 2012. Role of Saliva in the Oral Processing of Food. Food Oral Processing, Oxford: Wiley-Blackwell. pp. 45-60.

CHEN, J. 2009. Food oral processing - A review. Food Hydrocolloids. 23, 1-25. 10.1016/j.foodhyd.2007.11.013

CHRISTENSEN, C.M. 1986. Role of saliva in human taste perception. In Clinical Measurement of Taste and Smell (M.L. Meiselman and R.S. Rivlin, ed.) pp. 414-428, Macmillan, New York, United-States.

CHU, C.H., NG, A., CHAU, A.M. and LO, E.C. 2015. Oral health status of elderly chinese with dementia in Hong Kong. Oral Health Prev Dent. 13, 51-7.

COCHRAN, WG and COX, C.G. 1950. Experimental Designs. John Wiley and Sons, New York, United-States.

DODDS, M.W., JOHNSON, D.A. and YEH, C.K. 2005. Health benefits of saliva: a review. J Dent. 33, 223-33.

DORMENVAL, V., BUDTZ-JORGENSEN, E., MOJON, P., BRUYERE, A. and RAPIN, C.H. 1998. Associations between malnutrition, poor general health and oral dryness in hospitalized elderly patients. Age Ageing. 27, 123-8.

DSAMOU, M., PALICKI, O., SEPTIER, C., CHABANET, C., LUCCHI, G., DUCOROY, P., CHAGNON, M.C. and MORZEL, M. 2012. Salivary protein profiles and sensitivity to the bitter taste of caffeine. Chem Senses. 37, 87-95.

ENGELEN, L., VAN DEN KEYBUS, P.A., DE WIJK, R.A., VEERMAN, E.C., AMERONGEN, A.V., BOSMAN, F., PRINZ, J.F. and VAN DER BILT, A. 2007. The effect of saliva composition on texture perception of semi-solids. Arch Oral Biol. 52, 518-25. 10.1016/j.archoralbio.2006.11.007

ERICSSON, Y. 1953. [Clinical determination of salivary buffering]. Sven Tandlak Tidskr. 46, 379-86. 
ERNEST, S.L. 1993. Dietary intake, food preferences, stimulated salivary flow rate, and masticatory ability in older adults with complete dentitions. Spec Care Dentist. 13, 102-6.

FERON, G., AYED, C., QANNARI, E.M., COURCOUX, P., LABOURE, H. and GUICHARD, E. 2014. Understanding Aroma Release from Model Cheeses by a Statistical Multiblock Approach on Oral Processing. PLoS ONE. 9, e93113. 10.1371/journal.pone.0093113

FISCHER, U., BOULTON, R.B. and NOBLE, A.C. 1994. Physiological factors contributing to the variability of sensory assessments: Relationship between salivary flow rate and temporal perception of gustatory stimuli. Food Quality and Preference. 5, 55-64. $10.1016 / 0950-3293(94) 90008-6$

FLINK, H., BERGDAHL, M., TEGELBERG, A., ROSENBLAD, A. and LAGERLOF, F. 2008. Prevalence of hyposalivation in relation to general health, body mass index and remaining teeth in different age groups of adults. Community Dent Oral Epidemiol. 36, 52331.

FOLSTEIN, M.F., FOLSTEIN, S.E. and MCHUGH, P.R. 1975. "Mini-mental state". A practical method for grading the cognitive state of patients for the clinician. J Psychiatr Res. 12, 189-98.

GIERCZYNSKI, I., GUICHARD, E. and LABOURE, H. 2011. Aroma perception in dairy products: the roles of texture, aroma release and consumer physiology. A review. Flavour and Fragrance Journal. 26, 141-152. 10.1002/ffj.2036

GUIGOZ, Y. 2006. The Mini Nutritional Assessment (MNA) review of the literature - What does it tell us? J Nutr Health Aging. 10, 466-85.

HAMOSH, M. and BURNS, W.A. 1977. Lipolytic activity of human lingual glands (Ebner). Lab Invest. 37, 603-8.

HANDELMAN, S.L., BARIC, J.M., SAUNDERS, R.H. and ESPELAND, M.A. 1989. Hyposalivatory drug use, whole stimulated salivary flow, and mouth dryness in older, longterm care residents. Spec Care Dentist. 9, 12-8.

IKEBE, K., MATSUDA, K., KAGAWA, R., ENOKI, K., YOSHIDA, M., MAEDA, Y. and NOKUBI, T. 2011. Association of masticatory performance with age, gender, number of teeth, occlusal force and salivary flow in Japanese older adults: is aging a risk factor for masticatory dysfunction? Arch Oral Biol. 56, 991-6.

JOHANSON, C.N., OSTERBERG, T., LERNFELT, B., EKSTROM, J. and BIRKHED, D. 2015. Salivary secretion and drug treatment in four 70-year-old Swedish cohorts during a period of 30 years. Gerodontology. 32, 202-10.

LAGERLOF, F. and OLIVEBY, A. 1994. Caries-protective factors in saliva. Adv Dent Res. 8, 229-38.

LEAKE, J.L., HAWKINS, R. and LOCKER, D. 1994. Social and functional impact of reduced posterior dental units in older adults. J Oral Rehabil. 21, 1-10. 
LENANDER-LUMIKARI, M. and LOIMARANTA, V. 2000. Saliva and dental caries. Adv Dent Res. 14, 40-7.

NAGLER, R.M. and HERSHKOVICH, O. 2005. Relationships between age, drugs, oral sensorial complaints and salivary profile. Arch Oral Biol. 50, 7-16.

NEYRAUD, E., PALICKI, O., SCHWARTZ, C., NICKLAUS, S. and FERON, G. 2012. Variability of human saliva composition: Possible relationships with fat perception and liking. Archives of Oral Biology. 57, 556-566. 10.1016/j.archoralbio.2011.09.016

PEDERSEN, A.M., BARDOW, A., JENSEN, S.B. and NAUNTOFTE, B. 2002. Saliva and gastrointestinal functions of taste, mastication, swallowing and digestion. Oral Dis. 8, 117-29.

PRINZ, J.F. and LUCAS, P.W. 1997. An optimization model for mastication and swallowing in mammals. Proc Biol Sci. 264, 1715-21.

RAD, M., KAKOIE, S., NILIYE BROJENI, F. and POURDAMGHAN, N. 2010. Effect of Long-term Smoking on Whole-mouth Salivary Flow Rate and Oral Health. J Dent Res Dent Clin Dent Prospects. 4, 110-4.

ROUBENOFF, R., BAUMGARTNER, R.N., HARRIS, T.B., DALLAL, G.E., HANNAN, M.T., ECONOMOS, C.D., STAUBER, P.M., WHLSON, P.W. and KIEL, D.P. 1997. Application of bioelectrical impedance analysis to elderly populations. J Gerontol A Biol Sei Med Sei. 52, M129-36.

SALLES, C., CHAGNON, M.C., FERON, G., GUICHARD, E., LABOURE, H., MORZEL, M., SEMON, E., TARREGA, A. and YVEN, C. 2011. In-mouth mechanisms leading to flavor release and perception. Crit Rev Food Sci Nutr. 51, 67-90.

SALT, W.B., 2ND and SCHENKER, S. 1976. Amylase--its clinical significance: a review of the literature. Medicine. 55, 269-89.

SAMNIENG, P., UENO, M., SHINADA, K., ZAITSU, T., WRIGHT, F.A. and KAWAGUCHI, Y. 2012. Association of hyposalivation with oral function, nutrition and oral health in community-dwelling elderly Thai. Community Dent Health. 29, 117-23.

SCOTT, J. 1986. Structure and Function in Aging Human Salivary Glands. Gerodontology. 5, 149-158. 10.1111/j.1741-2358.1986.tb00062.x

SCOTT, J., FLOWER, E.A. and BURNS, J. 1987. A quantitative study of histological changes in the human parotid gland occurring with adult age. J Oral Pathol. 16, 505-10.

SHIP, J.A. 1992. Oral health of patients with Alzheimer's disease. J Am Dent Assoc. 123, 53 8.

SHIP, J.A., DECARLI, C., FRIEDLAND, R.P. and BAUM, B.J. 1990. Diminished submandibular salivary flow in dementia of the Alzheimer type. J Gerontol. 45, M61-6.

SHIP, J.A. and PUCKETT, S.A. 1994. Longitudinal study on oral health in subjects with Alzheimer's disease. J Am Geriatr Soc. 42, 57-63. 
SLADE, G.D. and SPENCER, A.J. 1994. Development and evaluation of the Oral Health Impact Profile. Community Dent Health. 11, 3-11.

SREEBNY, L.M. and SCHWARTZ, S.S. 1997. A reference guide to drugs and dry mouth-2nd edition. Gerodontology. 14, 33-47.

SRINIVASULU, G., FAREED, N., SUDHIR, K.M. and KRISHNA KUMAR, R.V. 2014. Relationship between stimulated salivary factors, dental caries status and nutritional condition among institutionalized elderly people. Oral Health Dent Manag. 13, 49-53.

STEEL, GD and ROBERT, R.T. 1980. Principles and Procedures of Statistics: a Biometrical Approach. McGraw-Hill, New York, United-States.

THOMSON, W.M. 2015. Dry mouth and older people. Aust Dent J. 1, 54-63.

THOMSON, W.M., CHALMERS, J.M., SPENCER, A.J. and WILLIAMS, S.M. 1999. The Xerostomia Inventory: a multi-item approach to measuring dry mouth. Community Dent Health. 16, 12-7.

TUBERT-JEANNIN, S., RIORDAN, P.J., MOREL-PAPERNOT, A., PORCHERAY, S. and SABY-COLLET, S. 2003. Validation of an oral health quality of life index (GOHAI) in France. Community Dent Oral Epidemiol. 31, 275-84. 
Table 1. Characteristics of the young and elderly panels.

\begin{tabular}{lllllll}
\hline & \multicolumn{3}{c}{ Young panel $(\mathbf{n = 9 3})$} & \multicolumn{3}{c}{ Elderly panel $(\mathbf{n}=\mathbf{8 4})$} \\
& $M$ & SEM & Range & M & SEM & Range \\
\hline Age & 38.94 & 8.37 & $22-55$ & 76.19 & 4.63 & $70-92$ \\
Number of teeth & & & & 21.40 & 9.00 & $0-32$ \\
Number of functional units & & & & 6.02 & 2.06 & $0-10$ \\
Resting salivary flow & 0.50 & 0.23 & $0.05-1.19$ & 0.31 & 0.19 & $0.03-0.86$ \\
Stimulated salivary flow & 2.47 & 1.06 & $0.70-5.45$ & 1.52 & 0.73 & $0.11-4.01$ \\
\hline
\end{tabular}

M: mean; SEM: standard error of the mean. 


\section{FIGURE 1}

Box-plot distributions of the resting (1.a) and stimulated (1.b) salivary flow for the young and elderly panels. The bottom and the top of the box correspond to the 25 th and 75 th percentile, respectively. The thick band corresponds to the median. The ends of the whiskers represent the lowest/highest data still within the 1.5 interquartile range. Any data points not included between the whiskers are plotted as outliers with a dot.
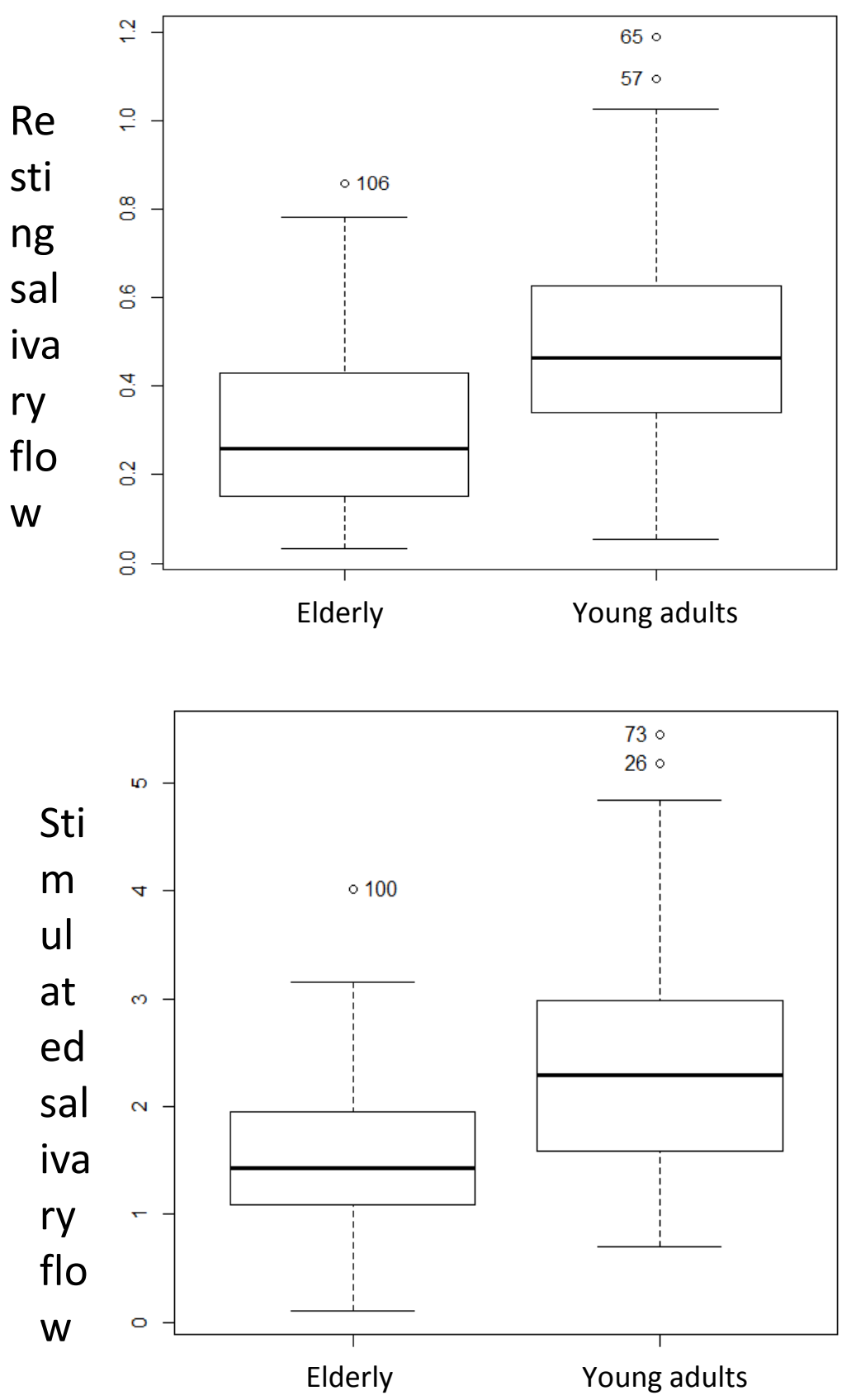


\section{FIGURE 2}

Representation of the resting (2.a) and stimulated (2.b) salivary flows for young adults, elderly with good dentition and elderly with poor dentition. The error bars correspond to the standard error of the mean. For each variable, the means with the same letter are not significantly different $(\mathrm{p}<.05)$. Resting (2.a): $\mathrm{M}_{\text {young }}=0.50 \mathrm{ml} / \mathrm{min} \pm 0.02 ; \mathrm{M}_{\text {elderly good dentition }}=$ $0.24 \mathrm{ml} / \mathrm{min} \pm 0.03 ; \mathrm{M}_{\text {elderly poor dentition }}=0.33 \mathrm{ml} / \mathrm{min} \pm 0.06$. Stimulated (2.b): $\mathrm{M}_{\text {young }}=02.46$ $\mathrm{ml} / \mathrm{min} \pm 0.11 ; \mathrm{M}_{\text {elderly good dentition }}=1.53 \mathrm{ml} / \mathrm{min} \pm 0.11 ; \mathrm{M}_{\text {elderly poor dentition }}=1.42 \mathrm{ml} / \mathrm{min} \pm 0.19$.

2.a

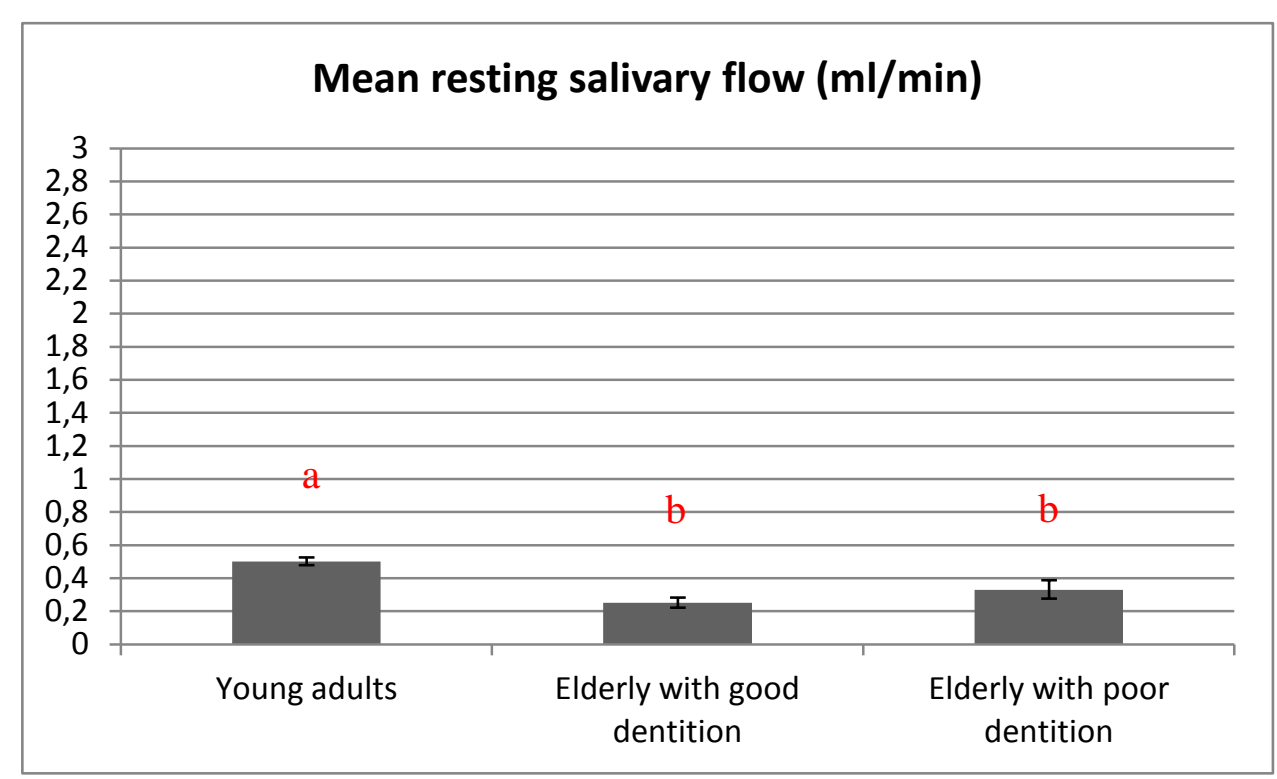

2.b

Mean stimulated salivary flow $(\mathrm{ml} / \mathrm{min})$

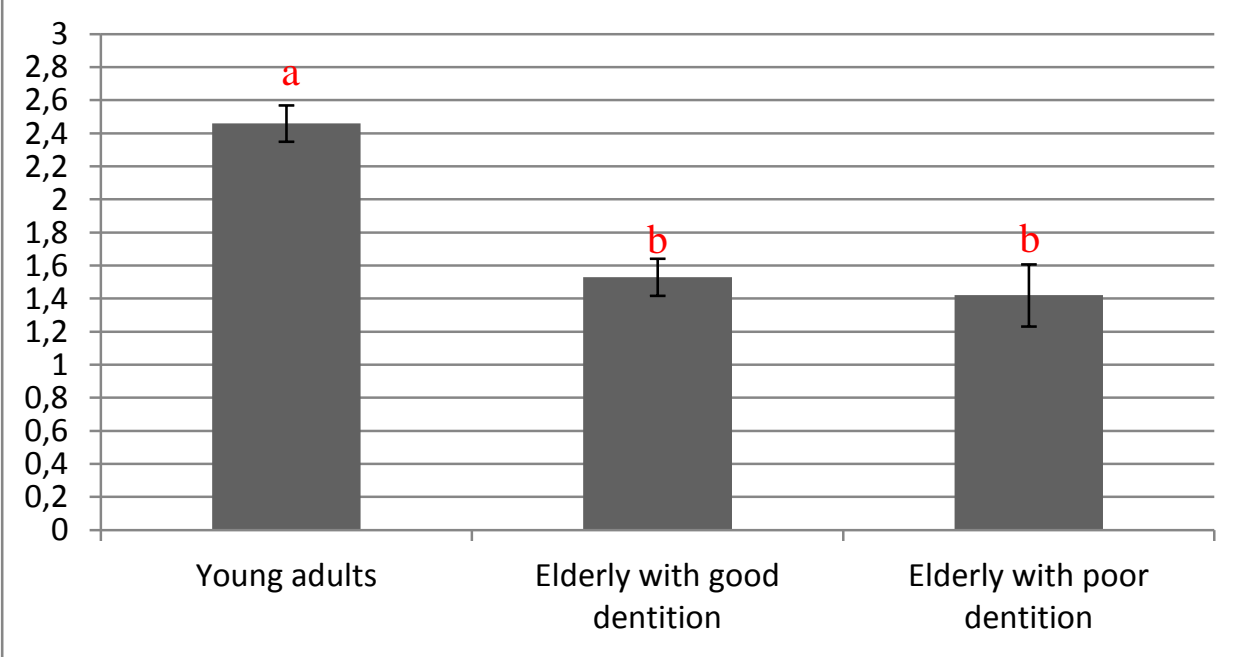




\section{FIGURE 3}

Representation of the resting (3.a) and stimulated (3.b) salivary flows for young adults, elderly drug free and elderly consuming drugs. The error bars correspond to the standard error of the mean. For each variable, the means with the same letter are not significantly different ( $\mathrm{p}<.05$ ). Resting (3.a): $\mathrm{M}_{\text {young }}=0.50 \mathrm{ml} / \mathrm{min} \pm 0.02 ; \mathrm{M}_{\text {elderly drug free }}=0.33 \mathrm{ml} / \mathrm{min} \pm 0.04$; $\mathrm{M}_{\text {elderly drug intake }}=0.30 \mathrm{ml} / \mathrm{min} \pm 0.02$. Stimulated (3.b): $\mathrm{M}_{\text {young }}=02.46 \mathrm{ml} / \mathrm{min} \pm 0.11 ; \mathrm{M}_{\text {elderly }}$ drug free $=1.45 \mathrm{ml} / \mathrm{min} \pm 0.13 ; \mathrm{M}_{\text {elderly drug intake }}=1.55 \mathrm{ml} / \mathrm{min} \pm 0.10$.

3.a

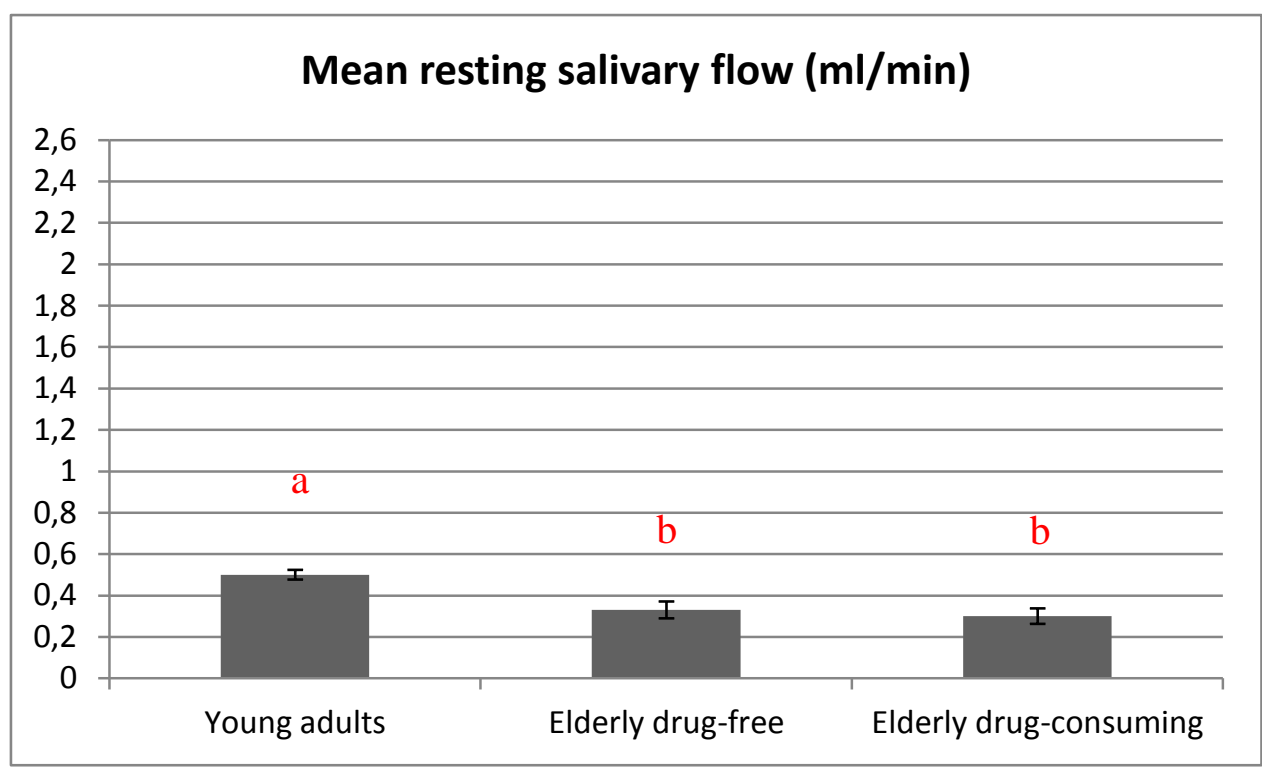

3.b

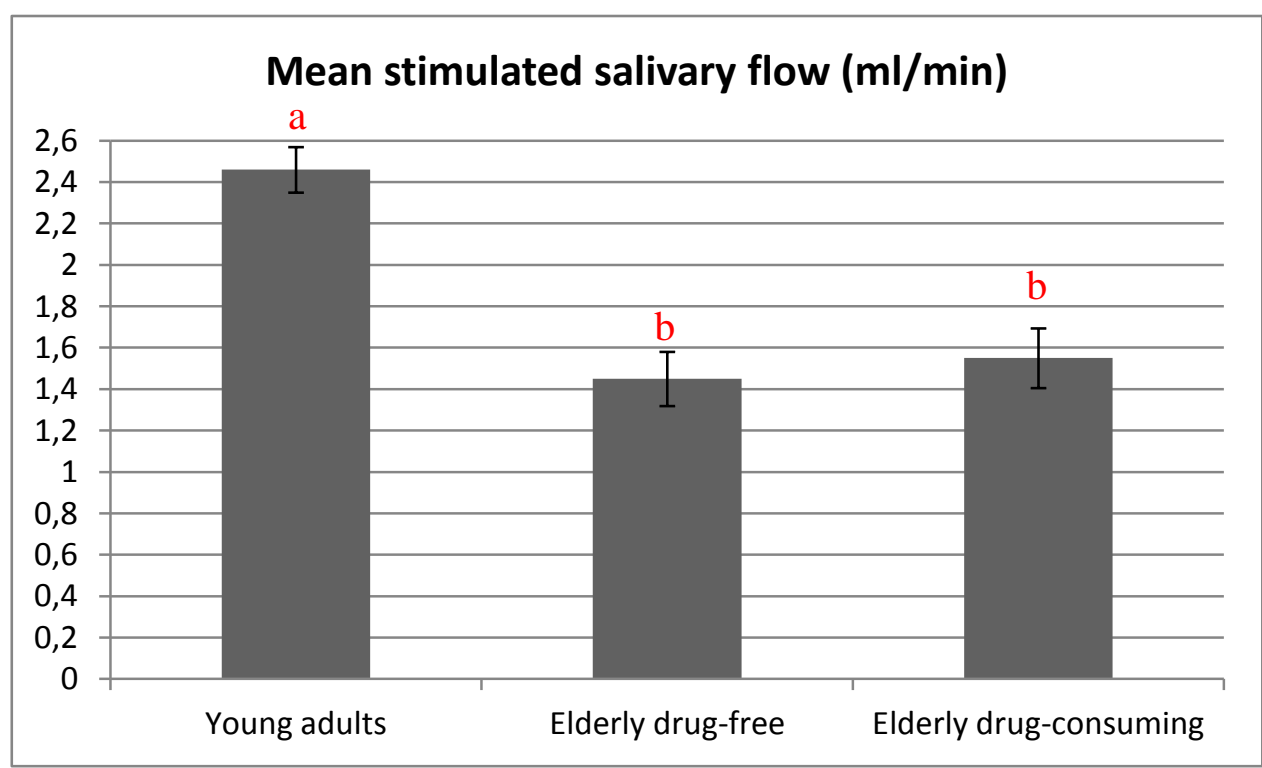




\section{FIGURE 4}

Representation of the factors likely to explain the variability observed in the elderly panel with respect to the salivary flow.

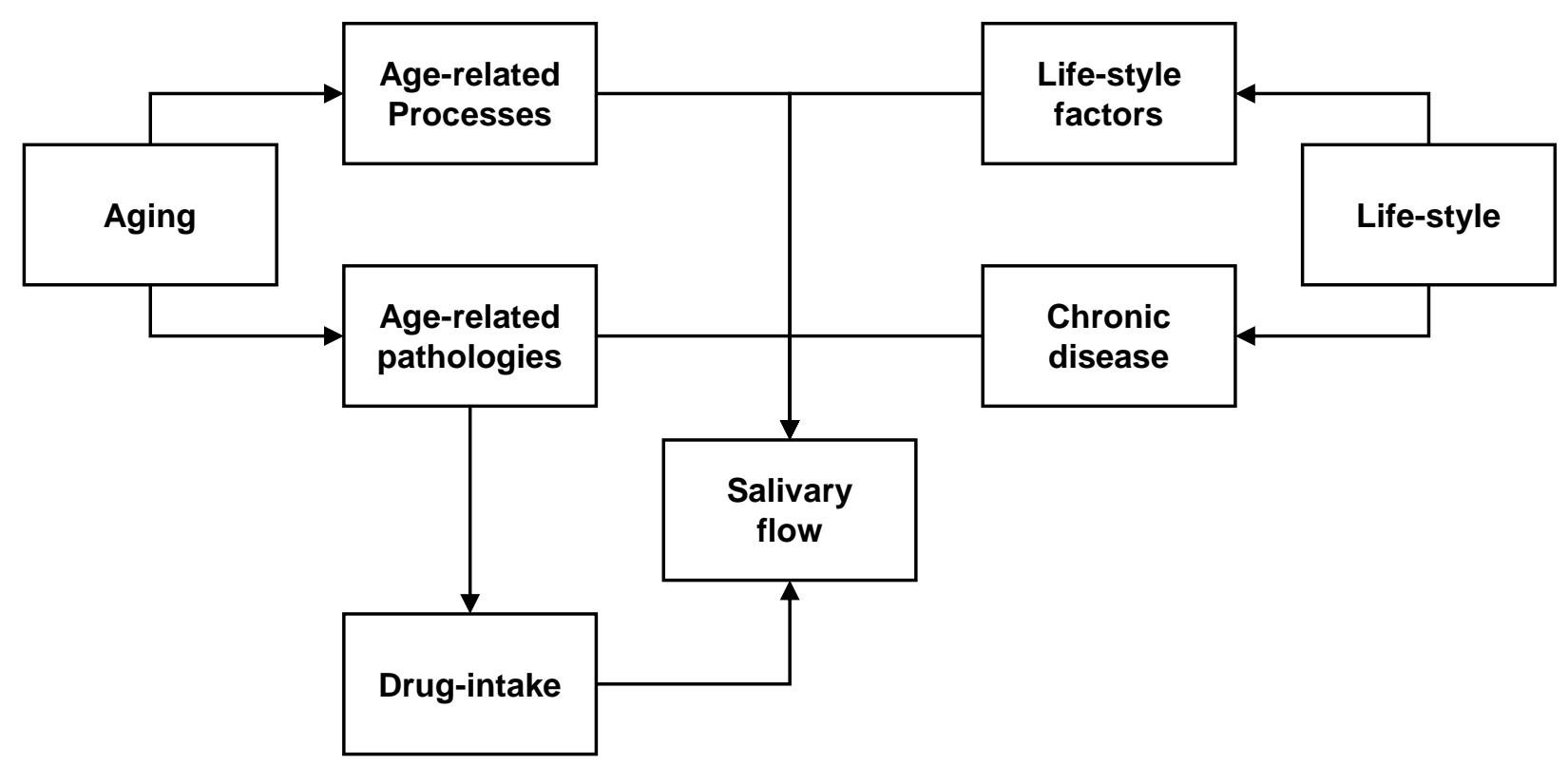

